\title{
TENSILE FORCE AND BENDING MOMENT DEMANDS ON HEADED STUD FOR THE DESIGN OF COMPOSITE STEEL PLATE SHEAR WALL
}

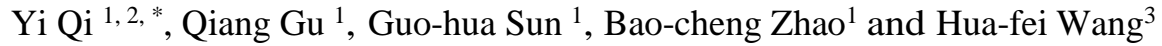 \\ ${ }^{1}$ School of Civil Engineering, Suzhou University of Science and Technology, Suzhou, China \\ ${ }^{2}$ Jiangsu Province Key Laboratory of Structure Engineering, Suzhou University of Science and Technology, Suzhou, China \\ ${ }^{3}$ College of Civil and Transportation Engineering, Hohai University, Nanjing 210098, China \\ *(Corresponding author: E-mail: qiyi7711@126.com)
}

\section{A B S T RACT}

The composite steel plate shear wall (C-SPW), composed of infill steel plate and reinforced concrete encasements, is widely used as a lateral load resisting system in high-rise buildings. The reinforced concrete encasement is connected to one or both sides of the infill steel plate using headed studs. Previous investigations have mainly focused on the seismic behaviour of C-SPWs and the bending failure of the connector, as explored in some experimental studies, are found before C-SPW achieve its target drift ratio. However, the behaviour of the headed stud, which plays an important role in the performance of C-SPWs, has been largely neglected. In this paper, a study of the tensile force and bending moment demands on headed studs in the design of C-SPWs is performed by using the finite element method. As the theoretical basis, the development, distribution and formation mechanisms of stud tension and bending moment are analysed. The effects of the headed stud diameter, number of headed studs, infill steel plate thickness, concrete panel thickness and panel aspect ratio on the stud performance are investigated. Based on this, available formulas for the tension and bending moment demands on headed studs in the design of C-SPWs are proposed.
A R T I C LE H IS T O RY

$\begin{array}{ll}\text { Received: } & \text { 8 October } 2018 \\ \text { Revised: } & \text { 01 May } 2019 \\ \text { Accepted: } & \text { 13 June } 2019\end{array}$

\section{K E Y W O R D S}

composite steel plate shear wall; stud tension;

stud bending moment; finite element analysis nonlinear buckling

Copyright $\odot 2019$ by The Hong Kong Institute of Steel Construction. All rights reserved.

\section{Introduction}

Composite steel plate shear walls (C-SPWs), which incorporate significant ductility, stiffness and energy dissipation capacity, are widely used as lateral load resisting systems in structural designs. In C-SPWs, the reinforced concrete encasement attached to one or both sides of the infill steel plate using headed studs is required to prevent the infill steel plate from buckling before yielding. As a result, the desired load-resisting mechanism of shear yielding in the infill steel plate can be realized. In cases of large story drift, infill steel plate elasto-plastic buckling behaviour may occur. Tension and bending of the headed studs become evident resulting from the relative out-of-plane deformation experienced between the infill steel plate and concrete encasements. To meet the expected ductility, shear resistance and energy dissipation of C-SPWs in instances of earthquake, the tensile force and bending moment demands on the headed studs in the design of C-SPWs are important issues that must be thoroughly explored. However, of the many available studies on C-SPWs, most focus on its seismic behaviour, with some experimental works finding that the correlative failure of connectors between the infill steel plate and concrete encasement occurs before the C-SPW reaches its expected drift ratio. In contrast, studies of the headed stud for the design of C-SPWs have not yet been undertaken.

One study of stud tension was proposed by Zhao and Astaneh-Asl [1, 2], where the headed stud was required to resist a tensile force induced by elasto-plastic local buckling of an infill steel plate. The test results of a one-story C-SPW captured by Arabzade et al. revealed that some of the bolts used to connect the concrete panel to the infill steel plate failed due to shear and bending resulting from inelastic buckling of the infill steel plate [3]. In an experimental investigation of C-SPWs with light-weight concrete panel bolted to the steel plate, Rassouli et al. reported significant bolt bending after inelastic local buckling of the steel plate [4]. AISC 341-10 contains several provisions for the design of C-SPWs: the minimum concrete panel thickness must be 100 $\mathrm{mm}$ when a concrete panel is provided on both sides of the steel plate and, otherwise, must be $200 \mathrm{~mm}$ when a concrete panel is provided on only one side of the steel plate; in addition, the reinforcement ratio in both directions shall not be less than $0.25 \%$ [5]

Studies on the effects of design parameters on the seismic behaviour of C-SPWs have also been reported. Rahai and Hatami, Shafaei et al. and Rahnavard et al. performed numerical or experimental studies on the effects of important design parameters (e.g., stud spacing, concrete panel thickness, etc.) on the seismic behaviour (e.g., maximum lateral resistance, out-of-plane displacement of the steel plate, maximum interstory drift, energy dissipation, etc.) of C-SPWs [6-8]. Dey and Bhowmick investigated the contributions of the infill steel plate, concrete panels and boundary columns to lateral resistance using nonlinear numerical analysis [9]. Using the Rayleigh-Ritz method, Smith et al. [10] and Arabzade et al. [11] proposed the local buckling coefficient for a unilaterally constrained rectangular plate under pure shear.
Various improvements to the structural elements in C-SPWs have been explored by researchers. An experimental study of the C-SPW in a composite frame under cyclic loading was conducted by Guo et al. [12]. A buckling-restrained steel plate shear wall (BR-SPW) was tested by Guo and Dong $[13,14]$. A comparison between the seismic behaviours of BR-SPWs and C-SPWs were made. A novel BR-SPW with inclined slots in the infill steel plate was theoretically and numerically analysed by Jin and Ou et al. [15]. A novel partially connected BR-SPW was theoretically and experimentally investigated by Wei et al. [16]. Compared to the traditional C-SPW, the aforementioned studies demonstrated that the corresponding improvements were beneficial to the structure's performance.

Few studies have explored the bearing capacity of headed studs in composite structures. Pallarés et al. comprehensively investigated the bearing capacity of headed studs under tension and combined tension and shear [17]. Lin et al. experimentally and numerically studied the behaviour of headed stud connections between concrete slabs and steel girders subjected to transverse bending moments [18]. The nominal tensile strengths of headed studs in composite structures are specified in ACI 318-11 [19], ACI 349-06 [20] and PCI 6th Edition [21].

Having a vital role to play in the behaviour of C-SPWs, the resistance demand on a headed stud should thus be treated as an important issue in the C-SPW design. The shear force demand on a headed stud and the concrete panel thickness demand for the design of C-SPWs was addressed previously by the authors [22, 23]. To date, however, there have been few studies of the tension or bending of headed studs due to the buckling of steel plates in the inelastic range of C-SPWs following the available design provisions or recommendations. In this paper, an investigation of the tensile force and bending moment demands on studs in seismic design of C-SPWs is conducted using the finite element method. This C-SPW consists of infill steel plate, cast-in-place reinforced concrete encasements with equal thickness on both sides of the steel plate as well as headed studs anchoring the concrete encasements to the steel plate. A validated finite element model incorporating an effective C-SPW behaviour prediction is established using ABAQUS /Standard [24]. Utilizing this validated finite element model, specific results regarding the nonlinear responses of headed studs in a C-SPW design under lateral loading are achieved. The finite element analyses are conducted for 27 specimens under monotonic lateral loadings with five variable design parameters including concrete panel thickness, infill steel plate thickness, panel aspect ratio (the ratio of the panel height to width) as well as the number of studs. The formation mechanisms of stud tension and bending moment are studied based on the interaction of the headed studs, infill steel plate and concrete panels, and the development and distribution of stud tension and bending moment are analysed. Fitting the collected tensile force and bending moment values of the headed studs when the drift ratios of C-SPWs reach $2.5 \%$, available formulas for the tension and bending moment demands on headed studs in the design of C-SPW are proposed, respectively. 


\section{Finite element model of C-SPW}

In the seismic design of this lateral load resisting system, which consists of a C-SPW and a boundary steel frame, the system is treated as C-SPWs entailing columns and beams, which are taken as a web plate, flange and stiffeners of a cantilever beam, respectively. Hence, the C-SPW undergoes shear deformation. To investigate the behaviours of headed studs in a C-SPW under shear loading, an in-plane shear load is applied to the infill steel plate, and a steel frame is introduced to the C-SPW to provide a boundary restriction without lateral resistance. In the finite element model (FEM) of the C-SPW, its boundary frame remains elastic with a hinged beam-column connection and simply supported base. Next, a monotonic lateral displacement is applied to the top beam. A finite element model of the C-SPW established using ABAQUS, which enables the inclusion of a hinged boundary frame and effectively takes into account the interactions between the infill steel plate, concrete panels, boundary frame and headed studs, as previously proposed and validated by the authors [22]. This FEM is employed to investigate the tensile force and bending moment on headed studs in this paper. The C-SPW evaluated here is characterized by cast-in-place reinforced concrete encasements attached to both sides of an infill steel plate, no gap between the concrete edges and a hinged single-bay one-story boundary steel frame. It should be mentioned that to avoid repetition, details regarding the element types, constitutive relationships governing materials, boundary conditions and validation of the FEM that can be found in [22] and are otherwise omitted here. The material properties as well as the interactions between finite elements are summarized below.

The plastic damage model, derived from Lubiner et al. [25] and Lee et al. [26], is utilized to depict the behaviour of the concrete material. The perfect elasto-plastic model is employed to model the constitutive relationships of the infill steel plate and reinforcing bar. The constitutive relationship of the headed stud is characterized by a bilinear hardening model with a hardening stiffness assumed to be $2 \%$ of the elastic stiffness. The material property of the boundary steel frame is assumed to maintain its elasticity in the finite element analysis.

Element types that include the infill steel plate, concrete panel, headed stud and reinforcing bar were reported in either prior finite element models of the C-SPW [8, 9] or steel-plate composite shear wall [27-29], which has a similar construction to that of the C-SPW. Herein, a 4-node reduced integration shell element (S4R) is utilized to model the infill steel plate; an 8 -node reduced integration solid element (C3D8R) is utilized to model the concrete panel; a 2-node linear beam element (B31) is utilized to model the headed stud; and a truss element (T3D2) is utilized to model the reinforcing bar. The boundary frame is simulated by coupling the shell element S4R to the beam element B31, where B31 enables the interaction between the boundary frame and infill steel plate and S4R enables the interaction between the boundary steel flanges and concrete panels. Because the steel frame provides elastic boundary restriction but no lateral stiffness to the C-SPW, tying its shell elements to the centroidal axis of the beam elements only slightly influences the inertia moment of the beam cross section as well as the axial force capacities of the beams and columns, thereby having no effect on the performance of the C-SPW.

The bonding action between the steel plate and cast-in-place concrete is commonly assumed to have a coefficient of friction [8, 29-31]. To model this bond action more practically, nonlinear spring elements (SPRING2) are adopted. A "hard" contact relationship without a friction effect is employed between the edges of the concrete panels and boundary steel flanges. The welded and embedded connections are realized by coupling all degrees of freedom of the overlap nodes.

Following the design provisions and recommendations of C-SPWs [1,2,5], five groups comprising 27 FEM specimens are established and analysed. The invariant information pertaining to each specimen is described in the following. The cross sections of the beams and columns are W530×219 and W360 $\times 818$, respectively. The nominal yield strength and ultimate strength of the headed studs are $240 \mathrm{MPa}$ and $400 \mathrm{MPa}$, respectively. For the infill steel plate, Young's modulus is $206 \mathrm{GPa}$; Poisson's ratio is 0.3 ; the nominal yield strength is $235 \mathrm{MPa}$; and the height $h$ is set as $3000 \mathrm{~mm}$. For the concrete panel, the cubic nominal tensile strength and cubic nominal compressive strength of concrete are taken as $2.01 \mathrm{MPa}$ and $20.1 \mathrm{MPa}$, respectively; Young's modulus is taken as $30 \mathrm{GPa}$; Poisson's ratio is 0.2 ; the reinforcement ratio is $0.75 \%$; and the nominal yield strength of the reinforcing bar is 300 $\mathrm{MPa}$.
In order to make the parametric study comprehensive, the design parameters are allowed to vary beyond the relevant requirements or recommendations. These variable parameters are listed in Table 1 , where $d_{\mathrm{st}}$ is the stud diameter; $t_{\mathrm{s}}$ is the infill steel plate thickness; $t_{\mathrm{c}}$ is the overall thickness of the concrete panels (the thickness of the concrete plate on each side is the same); the panel aspect ratio, defined as the ratio of the height $h$ to width $l$ of the shear wall, is denoted as $\alpha$; and the number of headed studs on one side of the infill steel plate is represented as $n_{\mathrm{x}} \times n_{\mathrm{y}}$, where $n_{\mathrm{x}}$ and $n_{\mathrm{y}}$ are the number of stud columns and rows, respectively. The stud diameters are taken as $16 \mathrm{~mm}$ and $22 \mathrm{~mm}$. Infill steel plate thicknesses of $10 \mathrm{~mm}, 15 \mathrm{~mm}$ and $20 \mathrm{~mm}$ are used. The overall concrete panel thicknesses that enable infill steel plate buckling in the inelastic range are set as $100 \mathrm{~mm}, 140 \mathrm{~mm}$ and $200 \mathrm{~mm}$. The stud spacings, calculated as $s_{\mathrm{st}}=l / n_{\mathrm{x}}=h / n_{\mathrm{y}}$, which are able to prevent local buckling of the infill steel plate are set as $750 \mathrm{~mm}, 600 \mathrm{~mm}, 500 \mathrm{~mm}$ and 300 $\mathrm{mm}$. Representative aspect ratios (the ratios of height to width) of one-story shear walls in engineering practice are considered to be 1.0 and 0.5 .

\section{The behaviour of the structural elements}

The behaviour of the structural elements of specimen N5-B under lateral loading is analysed to provide a mechanistic study of the tensile force and bending moment of the headed stud. The shear force developments in the C-SPW, infill steel plate and concrete panel are illustrated to analyze the performance of these members in the pre- and post-buckling of infill stee plate as well as the drift ratio corresponding to the onset of elasto-plastic bucking of the infill steel plate. It should be noted that the interaction between the infill steel plate, concrete panels and headed studs was presented in detail by the authors in [22]. Due to space limitations, this investigation focuses on the post-buckling phase. After infill steel plate buckling, the stud responses are governed by tension and bending, which results from the large relative out-of-plane deformation between the infill steel plate and concrete panels. The developments of stud tension and bending moment are analysed, allowing the critical drift ratio and critical stud locations to be obtained. The distributions of the tensile forces and bending moments in the stud group are plotted using vectors, in which the transfer mechanics of the tension and bending moment in the stud can be deduced based on the correlative responses of the infill steel plate and concrete panels.

The location of the headed stud is represented by HS- $i-j-\mathrm{A}$ or HS-i-j-B, where $i$ is the numbering of the stud column from left to right; $j$ is the numbering of the stud row from top to bottom; "A" is the side of the infill steel plate in the positive direction of the Z-axis and " $\mathrm{B}$ " is the other side.

\subsection{Development of shear force and deformation}

The shear force-drift ratio curves of specimen N5-B are shown in Fig. 1, where $V, V_{\mathrm{s}}$ and $V_{\mathrm{c}}$ are the shear forces of the C-SPW, infill steel plate and concrete panel, respectively. It can be observed that the shear force developments of the C-SPW and steel plate are divided into two phases, i.e., the pre- and post-buckling phases. The lateral resistance of the C-SPW is primarily governed by the infill steel plate. In pre-buckling, both elastic and yielding phases of the infill steel plate are involved. In the elastic phase, all curves ascend linearly, and the maximum shear force of the concrete panel appears, while the infill steel plate remains elastic. In the yielding phase, the shear force-drift ratio curve of the C-SPW, $V-\theta$, reaches the maximum value $V_{\mathrm{y}}=6660.7 \mathrm{kN}$, and then slowly declines; a plateau develops in the $V_{\mathrm{s}}-\theta$ curve as shear yield occurs in the infill steel plate; and the $V_{\mathrm{c}}-\theta$ curve gradually declines resulting from significant degradation of the concrete. In the post-buckling phase, the $V-\theta$ and $V \mathrm{~s}-\theta$ curves sharply drop due to the inelastic buckling of the infill steel plate; then, the rate of decrease of both curves tends to decrease due to the lateral resistance of the diagonal tension field in the infill steel plate. The critical drift ratio, denoted as $\theta_{\mathrm{b}}$, is $1.36 \%$.

The out-of-plane deflection development of the infill steel plate is illustrated in Fig. 2. The curve of steel plate deflection-drift ratio, $D_{\mathrm{sp}}-\theta$, is minimal in the pre-buckling phase; after the onset of buckling in the infill steel plate, the deflection suddenly ascends, followed by gradual slowing of this increasing trend. This remarkable increase in the deflection behaviour is triggered by buckling of the infill steel plate. Owing to the restraint from the concrete panels, the increasing trend is abated. The beginning of the increase in deflection corresponds with the decrease of the shear forces in the C-SPW and infill steel plate, which demonstrates that the critical drift ratio $\theta_{\mathrm{b}}$ occurs at the commencement of infill steel plate buckling. 
Table 1

Finite element specimen details.

\begin{tabular}{|c|c|c|c|c|c|c|}
\hline Groups & Specimens & $d_{\mathrm{st}}(\mathrm{mm})$ & $n_{\mathrm{x}} \times n_{\mathrm{y}}$ & $t_{\mathrm{s}}(\mathrm{mm})$ & $t_{\mathrm{c}}(\mathrm{mm})$ & $\alpha$ \\
\hline \multirow[t]{6}{*}{ N4 } & N4-B & 16 & $4 \times 4$ & 15 & 140 & 1 \\
\hline & N4-D22 & 22 & $4 \times 4$ & 15 & 140 & 1 \\
\hline & N4-TS10 & 16 & $4 \times 4$ & 10 & 140 & 1 \\
\hline & N4-TS20 & 16 & $4 \times 4$ & 20 & 140 & 1 \\
\hline & N4-TC50 & 16 & $4 \times 4$ & 15 & 100 & 1 \\
\hline & N4-TC100 & 16 & $4 \times 4$ & 15 & 200 & 1 \\
\hline \multirow[t]{6}{*}{ N5 } & N5-B & 16 & $5 \times 5$ & 15 & 140 & 1 \\
\hline & N5-D22 & 22 & $5 \times 5$ & 15 & 140 & 1 \\
\hline & N5-TS10 & 16 & $5 \times 5$ & 10 & 140 & 1 \\
\hline & N5-TS20 & 16 & $5 \times 5$ & 20 & 140 & 1 \\
\hline & N5-TC50 & 16 & $5 \times 5$ & 15 & 100 & 1 \\
\hline & N5-TC100 & 16 & $5 \times 5$ & 15 & 200 & 1 \\
\hline \multirow[t]{6}{*}{ N6 } & N6-B & 16 & $6 \times 6$ & 15 & 140 & 1 \\
\hline & N6-D22 & 22 & $6 \times 6$ & 15 & 140 & 1 \\
\hline & N6-TS10 & 16 & $6 \times 6$ & 10 & 140 & 1 \\
\hline & N6-TS20 & 16 & $6 \times 6$ & 20 & 140 & 1 \\
\hline & N6-TC50 & 16 & $6 \times 6$ & 15 & 100 & 1 \\
\hline & N6-TC100 & 16 & $6 \times 6$ & 15 & 200 & 1 \\
\hline \multirow[t]{6}{*}{ N10 } & N10-B & 16 & $10 \times 10$ & 15 & 140 & 1 \\
\hline & N10-D22 & 22 & $10 \times 10$ & 15 & 140 & 1 \\
\hline & N10-TS10 & 16 & $10 \times 10$ & 10 & 140 & 1 \\
\hline & N10-TS20 & 16 & $10 \times 10$ & 20 & 140 & 1 \\
\hline & N10-TC50 & 16 & $10 \times 10$ & 15 & 100 & 1 \\
\hline & N10-TC100 & 16 & $10 \times 10$ & 15 & 200 & 1 \\
\hline \multirow[t]{3}{*}{ L6 } & L6-B & 16 & $5 \times 10$ & 15 & 140 & 0.5 \\
\hline & L6-TS10 & 16 & $5 \times 10$ & 15 & 140 & 0.5 \\
\hline & L6-TS20 & 16 & $5 \times 10$ & 15 & 140 & 0.5 \\
\hline
\end{tabular}

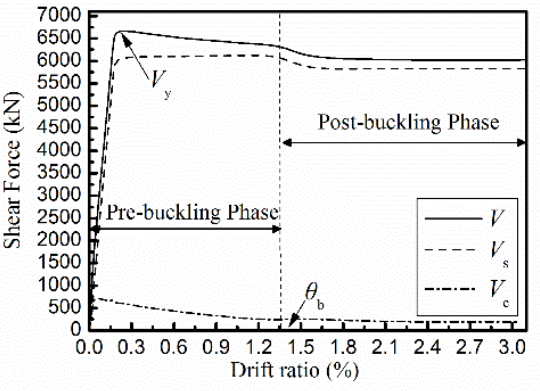

Fig. 1 Shear force-drift ratio curves of N5-B

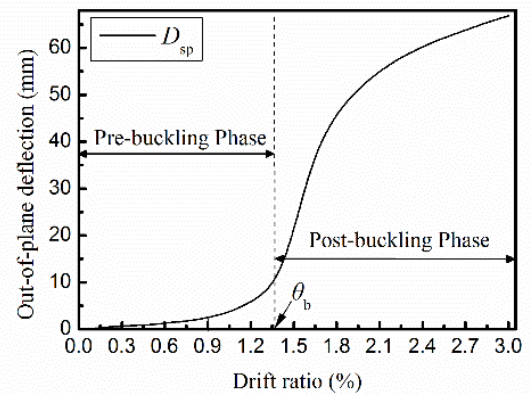

Fig. 2 Infill steel plate deflection-drift ratio curve of N5-B

\subsection{Developments of tension and bending moment in the stud}

In this section, the tensile force- and bending moment-drift ratio relationships of the representative studs in N5-B are analysed. The effects of design parameters on the stud tension and bending moment are discussed in the next chapter. As shown in Fig. 3, it is observed that the curves of HS-1-5-B and HS-5-1-B exhibit small peak values in the pre-buckling phase, which indicates that the infill steel plate and concrete panels have begun to separate at the wall corners. At the critical drift ratio $\theta_{\mathrm{b}}=1.36 \%$, the curves start to increase due to buckling of the infill steel plate. The increase of this curve in the post-buckling phase of the steel plate is divided into two stages, where the first is defined as Increase Stage 1 exhibiting a rapid rate of increase, and the second is defined as Increase Stage 2 incorporating a relatively slow rate of increase. This pattern has correspondence with the out-of-plane deflection of the infill steel plate. The tensile forces of critical tensile studs are almost identical.

As shown in Fig. 4, the representative bending studs in N5-B exhibit similar development patterns. In the pre-buckling phase, small peak values are found in some of the curves, resulting from relative in-plane shear deformation between the infill steel plate and concrete panels. At the critical drift ratio $\theta_{\mathrm{b}}=1.36 \%$, the curves start to rise. Two stages are observed in the post-buckling phase, as illustrated in Fig. 4. In the Increase Stage, the stud bending moments increase linearly. In the Plateau Stage, the curve holds approximately constant, and the curve appears to plateau. The bending moments of the critical bending studs are almost identical.

It can be concluded that the tension and bending moment stud becomes evident in the post-buckling phase. The critical drift ratio $\theta_{\mathrm{b}}$ can be determined from the second inflection point in the stud tension- and bending moment-drift 
ratio curves. The locations of the critical stud with relatively large tensile forces and bending moments are accordingly recorded according to these curves. The relationship between the locations of the critical studs and buckling half-wave of the infill steel plate are discussed below.

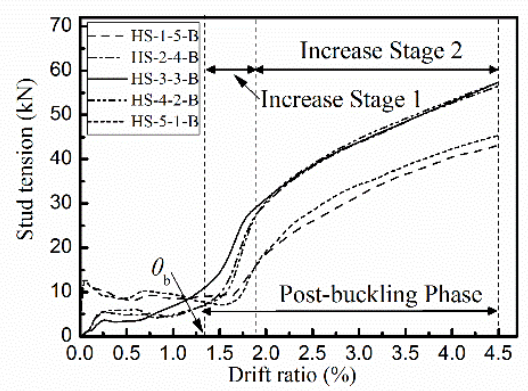

Fig. 3 Stud tension developments of N5-B

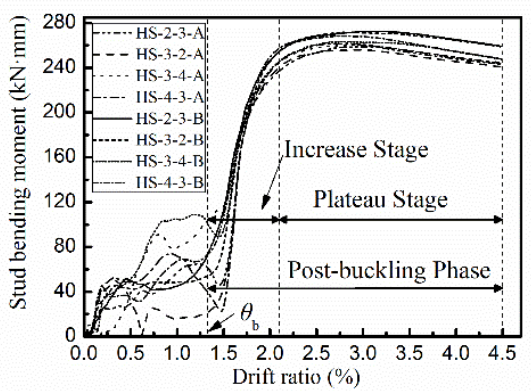

Fig. 4 Stud bending moment developments of N5-B

\subsection{Distributions of stud tension and bending moment}

The buckling mode of the infill steel plate and the distributions of stud tension and bending moment are illustrated in Figs. 5 and 6, respectively. These distributions are displayed using vectors, where the direction of the stud bending moment transferred through the concrete panel is defined by the right-hand rule (bending moments of studs on the "A" side of the infill steel plate are displayed representatively). As shown in Fig. 5, a single buckling half-wavelength of the steel plate develops approximately along the $45^{\circ}$ direction, which results from the principal compressive stress. A global inelastic buckling takes place in the infill steel plate. According to the numbering of the headed studs plotted in Fig. 5 and referring to the curves in Figs. 3 and 4 illustrating the representative studs with relatively large tensile forces and bending moments, it is known that the critical tensile studs are concentrated in the middle of the buckling half-wave on the one side of the infill steel plate; the critical bending studs are at the boundary of buckling half-wave on both sides of the infill steel plate. These tensile forces on the "B" side and bending moments on the "A" side at the drift ratio of $3.3 \%$ are expressed using vectors in Fig. 6. The magnitudes of the vectors indicate that the tensile forces and bending moments of the critical studs have almost identical values, respectively. The direction of stud tension is in contrast to that of the out-of-plane displacement of the infill steel plate in the middle of the buckling half-wave. The direction of the stud bending moment is contrary to that of the out-of-plane rotation of the infill steel plate at the boundary of the buckling half-wave. The bending studs at each end of the buckling half-wave have directions consistent with reverse moments.

The relevant interactions between the headed studs, infill steel plate and concrete panels after the global inelastic buckling of the infill steel plate can therefore be deduced from Figs. 7. As displayed in Fig. 7 (a), the tensile force in the headed stud transferred through the concrete panel on side "B" at the peak of the buckling half-wave is the largest, resulting from the significant out-of-plane displacement of the infill steel plate. As displayed in Fig. 7 (b), the bending moments of the headed studs transferred through the concrete panel on both sides at the boundary of the buckling half-wave are the largest due to the relatively significant out-of-plane rotation of the infill steel plate at the same location. It is important to note that at the location of the critical tensile stud, i.e., the peak of the half-wave, the bending moment transfer is tiny attributed to the insufficient rotation; in contrast, at the location of the critical bending stud, i.e., the boundary of the half-wave, the tensile force transfer is weak owing to the slight displacement. Consequently, the coupling effects of the tensile force and bending moment of the headed stud can be neglected, and studies of the stud tension and bending moment in C-SPW design can be performed independently.

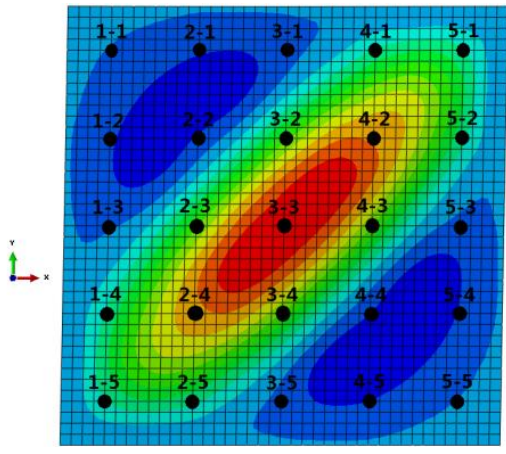

Fig. 5 Out-of-plane deformation of N5-B

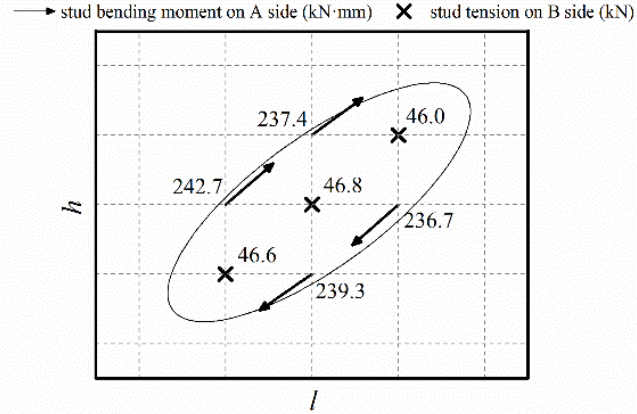

Fig. 6 Distributions of stud tension and bending moment in N5-B

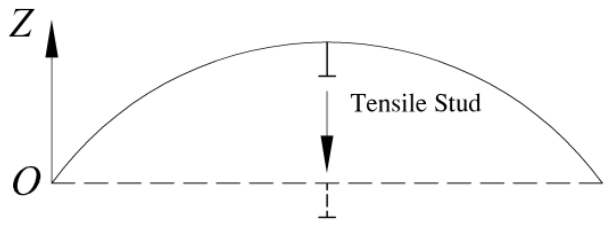

(a) Tensile stud

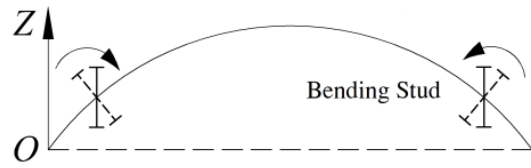

(b) Bending studs

Fig. 7 Schematics of tensile and bending studs

\section{Parametric study on tensile force and bending moment of stud}

The effects of stud diameter, number of headed studs, steel plate thickness, concrete panel thickness and panel aspect ratio on the stud tension and bending moment are analysed, respectively. Since the tensile forces and bending moments in the critical studs are almost identical, the tensile force and bending 
moment developments in the headed studs are analysed using the largest results for each case individually. The development stages as well as the maximums of stud tension and bending moment corresponding to the drift ratio of $2.5 \%$, which is the limitation required by ASCE [32], are recorded for formula fitting. The relationships between the internal force of the infill steel plate and the tensile force and bending moment of the headed stud are established to provide the embryonic forms of the final proposed formulas.

\subsection{Parameter analysis on stud tension}

Stud tension-drift ratio curves are shown in Figs. 8. It is observed that the onset of tensile force development is determined by the critical drift ratio corresponding to the inelastic buckling of the infill steel plate, which is reflected at the second inflection point of each curve. All curves exhibit the same development pattern including the stage before increasing, i.e., the pre-buckling phase of the C-SPW, Increase Stage 1 and Increase Stage 2, referring to Fig. 3. Stud tension is small in the pre-buckling phase; Increase Stage 1 exists transitorily, where the tensile force rapidly increases; and in

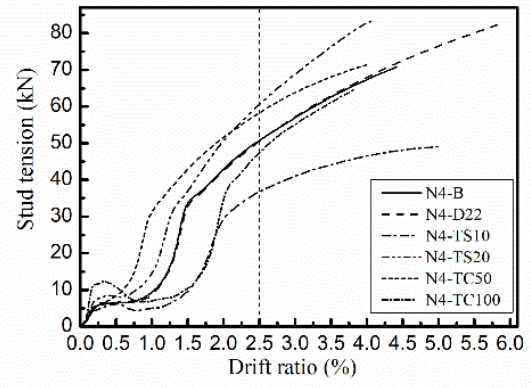

(a) N4 Group

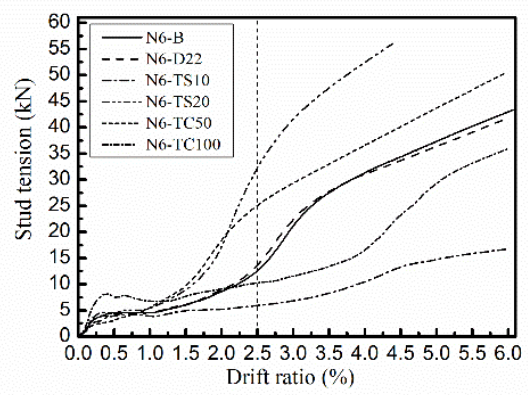

(c) N6 Group
Increase Stage 2, the rate of increase of the tensile force tends to be slow.

It follows from Fig. 8 that the critical drift ratio increases with the increment of the steel plate thickness, stud spacing and panel aspect ratio as well as with the reduction of the concrete panel thickness. In Increase Stage 1, the stud tension increases with the increment of the panel aspect ratio, the stud spacing and the ratio of infill steel plate thickness to concrete panel thickness. The curve shapes in Increase Stage 2 are approximately straight lines, where the slope increases with the increment of the infill steel plate thickness, panel aspect ratio and stud spacing. Throughout the entire developmental trend, stud tension is independent of stud diameter.

At a certain drift ratio, the magnitude of stud tension depends on three factors: the critical drift ratio corresponding to the beginning of infill steel plate buckling, the development stage where the tensile force is located and the slope of the tensile force-drift ratio curve, i.e., the rate of increase of the tensile force. As a result, the formula for the maximum stud tension when the drift ratio reaches $2.5 \%$ can be fitted based on the results of the parameter analysis presented here.

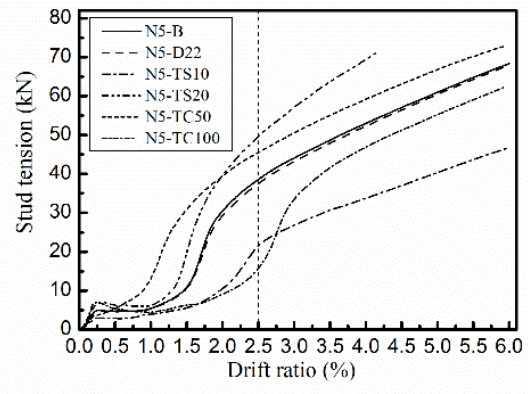

(b) N5 Group

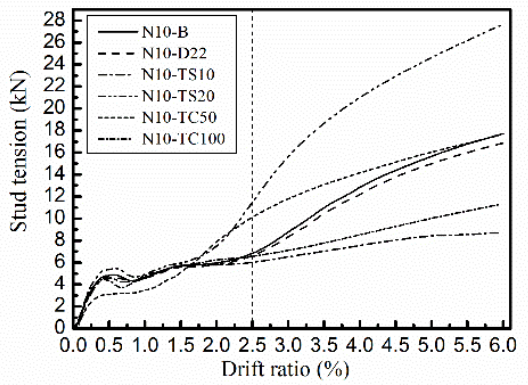

(d) N10 Group

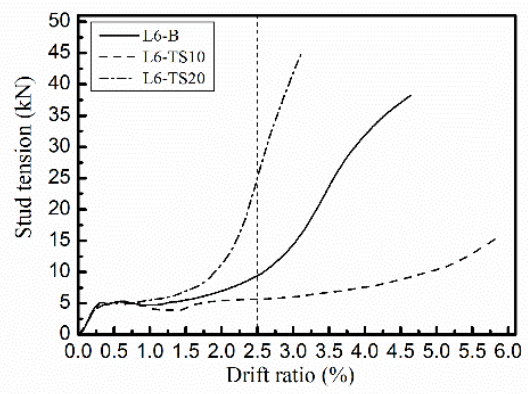

(e) L6 Group

Fig. 8 Tensile force developments of studs

\subsection{Parameter analysis on stud bending moment}

Stud bending moment-drift ratio curves are illustrated in Figs. 9. The bending moment developments commence at the second inflection points in the curves associated with the buckling of the infill steel plate. All curves exhibit the same development pattern including the stage before infill steel plate buckling, the Increase Stage and the Plateau Stage, as presented in Fig. 4. The stud bending moment is relatively small in the stage before infill steel plate buckling; in the Increase Stage, the stud bending moment increases linearly; and in the Plateau Stage, the curve reaches its maximum and then continues at an approximately constant value.

The commencement of bending moment development corresponds with the onset of tensile force. For the Increase Stage, increasing the infill steel plate thickness, stud spacing, stud diameter and panel aspect ratio and reducing the 
concrete panel thickness increase the slope of this curve. It should be noted that the stud diameter and stud length that varies with concrete thickness have correlation with stud bending stiffness which also affects the curve slope. For the Plateau Stage, the maximum value of stud bending moment that can be achieved is largely due to the stud diameter and infill steel plate thickness. In the same specimen group, it can be observed from the curves that the maximum stud bending moments of specimens with an infill steel plate thickness of 10 $\mathrm{mm}$ are smaller and the maximum stud bending moments of specimens with a

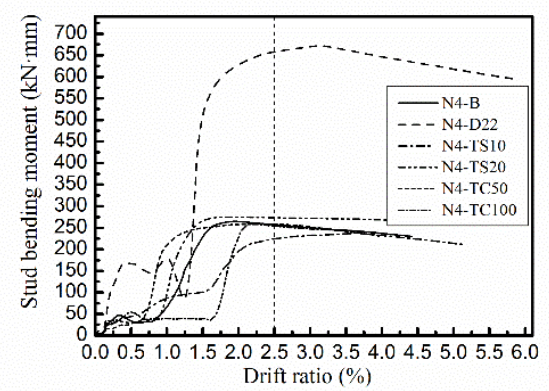

(a) N4 Group

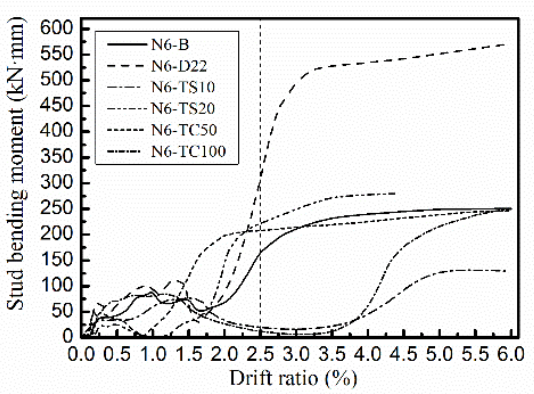

(c) N6 Group stud diameter of $22 \mathrm{~mm}$ are larger, whereas the stud spacing, concrete panel thickness and panel aspect ratio only slightly affect the stud bending moment.

Developing the same conclusion as that for stud tensile force, the stud bending moment at a certain drift ratio is determined by the critical drift ratio, the development stage as well as the slope of the curve. The formula for the maximum stud bending moment when the drift ratio reaches $2.5 \%$ can be fitted based on the pertinent parameter analysis results above.

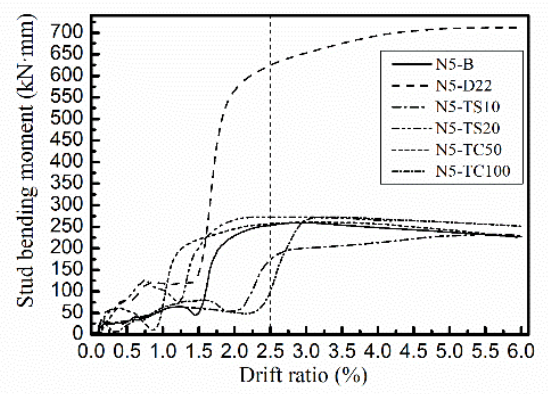

(b) N5 Group

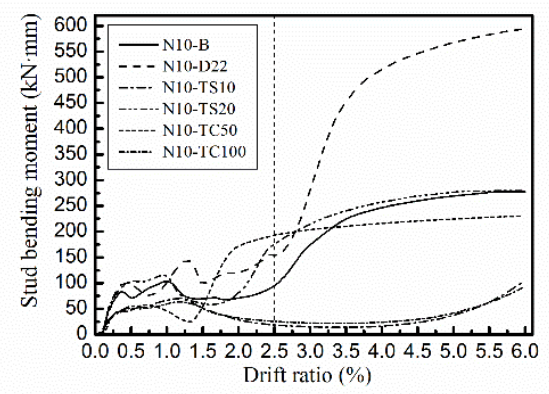

(d) N10 Group

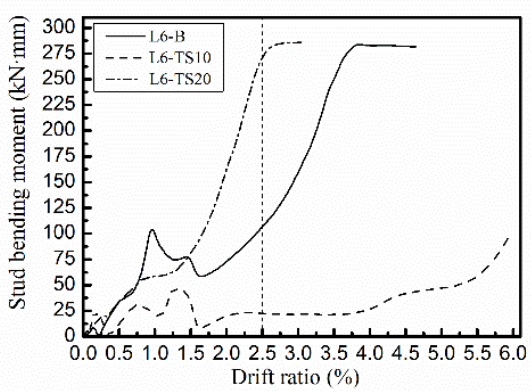

(e) L6 Group

Fig. 9 Bending moment developments of studs

\subsection{Interaction between headed stud and infill steel plate}

The interaction between the headed stud and infill steel plate in the post-buckling phase is investigated utilizing the vectors of stud tension and bending moment as well as the out-of-plane deformation of the infill steel plate. The finite element analysis results reveal that the stud tension and bending moment exhibit the same distribution pattern indicating that the critical tensile studs are concentrated in the middle of the buckling half-wave of the infill steel plate while the critical bending studs reside at the boundary. However, as the number of studs or panel aspect ratio is varied, the locations and the number of critical studs differ. To illustrate the relationship between the buckling half-wave of the steel plate and locations of the critical studs, representative specimens for the various groups are thus selected: N4-B, N6-B, N10-B and L6-B (analyses of specimen N5-B are presented in Section 3). Accounting for the different critical drift ratios of the specimens, the vectors of the critical headed stud and the out-of-plane deformation of the steel plate are displayed at a relatively large constant drift ratio of $4.0 \%$.

As plotted in Figs. 10-13, the buckling modes imply that all specimens incur global inelastic buckling in the infill steel plate, in which L6-B is characterized by two buckling half-waves. Decreasing the stud spacing increases the buckling half-wavelength, thereby increasing the number of critical tensile and bending studs. The buckling half-waves of specimens N4-B, N6-B and N10-B with a panel aspect ratio of 1.0 incline approximately along the $45^{\circ}$ direction, whereas the buckling half-waves in L6-B with a panel aspect ratio of 0.5 develop at a slightly smaller angle than $45^{\circ}$. This finding leads to a larger number of critical studs as the panel aspect ratio is reduced. The magnitudes of the tensile forces and bending moments of the critical studs within the buckling half-wave of the infill steel plate are relatively close to each other. The directions of the tensile forces and bending moments of the critical studs are contrary to that of the out-of-plane deformation of the infill steel plate. The coupling effect of the tensile force and bending moment of the assessed critical stud is minimal. 


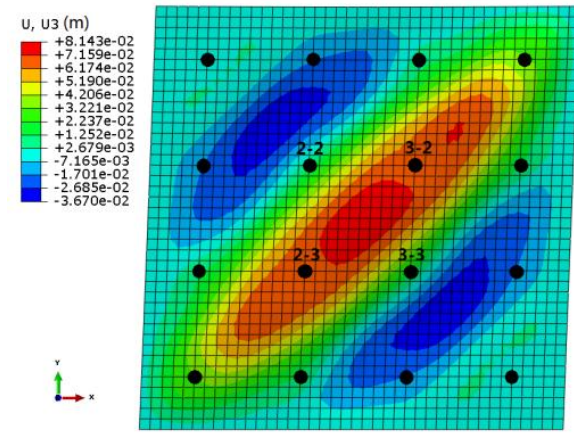

(a) Out-of-plane deformation of steel plate

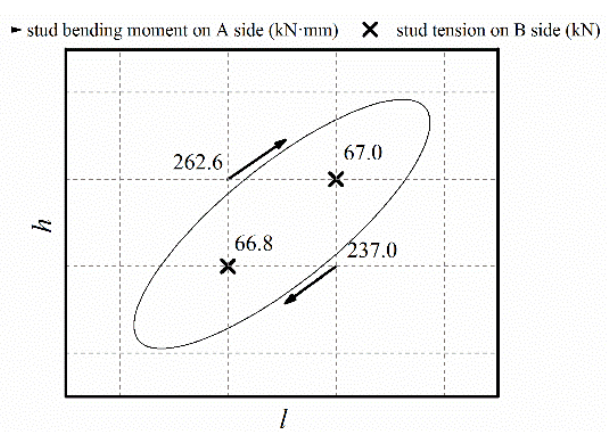

(b) Tensile forces and bending moments of studs

Fig. 10 Relationship between the critical studs and buckling half-wave of N4-B

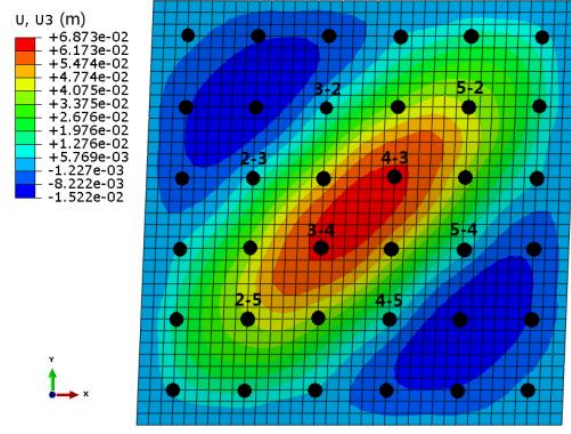

(a) Out-of-plane deformation of steel plate

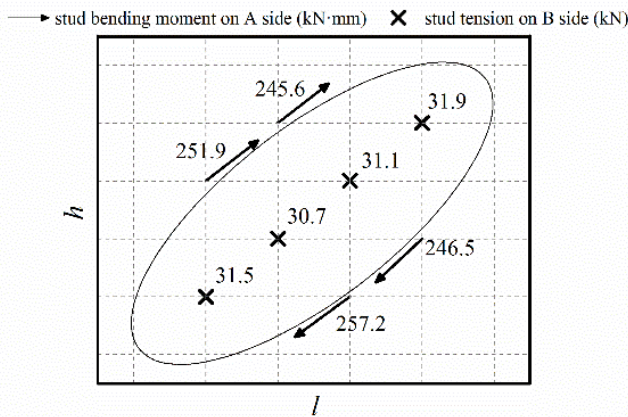

(b) Tensile forces and bending moments of studs

Fig. 11 Relationship between the critical studs and buckling half-wave of N6-B

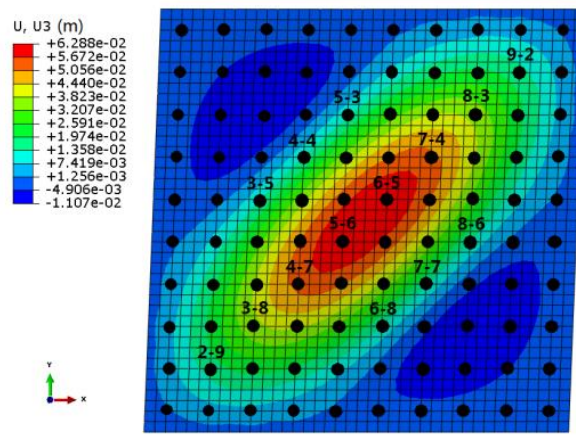

(a) Out-of-plane deformation of steel plate

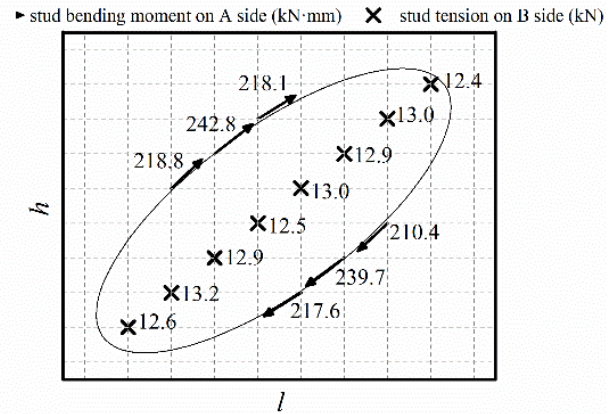

(b) Tensile forces and bending moments of studs

Fig. 12 Relationship between the critical studs and buckling half-wave of N10-B

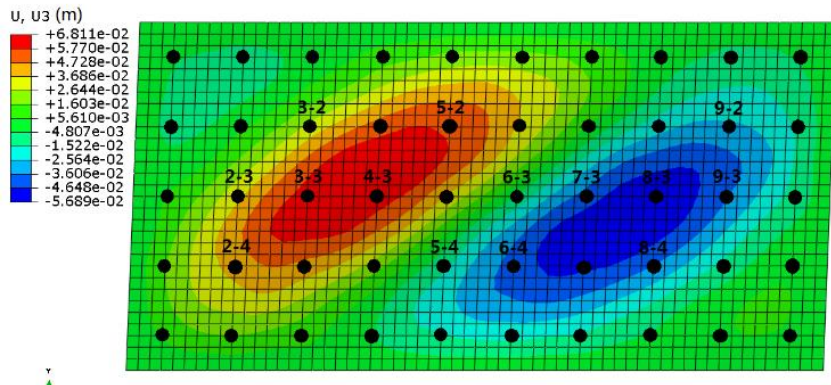

(a) Out-of-plane deformation of steel plate

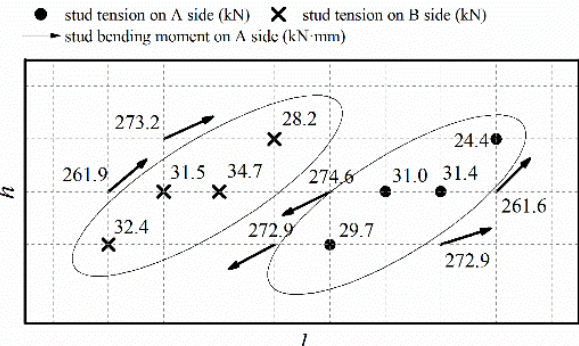

(b) Tensile forces and bending moments of studs

Fig. 13 Relationship between the critical studs and buckling half-wave of L6-B

According to the distribution of the critical tensile and bending studs analysed above, the interaction among structural elements after the onset of global inelastic buckling of the infill steel plate can be inferred. As shown in Fig.
14 (a), the critical tensile and bending studs are analysed in two independent plate strips of infill steel plate, respectively, where $w$ is the half-wavelength (plate strip length), and $s$ is the diagonal stud spacing along the $45^{\circ}$ direction 
(plate strip width). In one plate strip, one headed stud on a single side in the middle of the buckling half-wave is covered to analyze the tension in the stud. In another plate strip, four headed studs on both sides at the boundary of the buckling half-wave are covered to analyze the stud bending moment. The width of the assigned plate strip $s$ reduces with the decrease of stud spacing and panel aspect ratio due to the different numbers of studs located in the buckling half-wave as well as the area in which the buckling half-wave develops.

The responses of headed studs after infill steel plate buckling in each plate strip are illustrated in Fig. 14 (b). Based on static equilibrium, the tensile force of stud $F_{\mathrm{b}}$ is determined by the transverse component of the axial forces at both ends of the analysed plate strip; the bending moments $M_{\mathrm{s}}$ at both ends of the plate strip cancel each other out. Because infill steel plate buckling occurs after shear yielding, this axial force can be deduced to be $\eta F_{\text {sy }}$, where $F_{\text {sy }}=s t_{s} f_{\mathrm{sy}}$ is the axially yield strength of the plate strip $\left(f_{\mathrm{sy}}\right.$ is the yield strength of the steel and $t_{\mathrm{s}}$ is the thickness of the steel plate or plate strip), and $\eta$ is the proportion of $F_{\text {sy }}$ that axial force achieves throughout the development of the buckling half-wave. Taking into account the effects of the stud spacing $s_{\mathrm{st}}$ and panel aspect ratio $\alpha$ on the plate strip width $s$ as well as the axial force $\eta F_{\text {sy }}$ in direct proportion to its transverse component, the relationship between the tensile force in the stud after steel plate buckling and the internal force of the infill steel plate is established as Eq. (1), where $F_{\mathrm{b}}$ is the stud tension in $\mathrm{kN} ; f_{\mathrm{sy}}$ is the infill steel plate yield strength in MPa; $t_{\mathrm{s}}$ is the infill steel plate thickness in $\mathrm{mm} ; s_{\mathrm{st}}$ is the stud spacing in $\mathrm{mm} ; \alpha$ is the panel aspect ratio; and $\beta_{\mathrm{f}}$ is the dimensionless

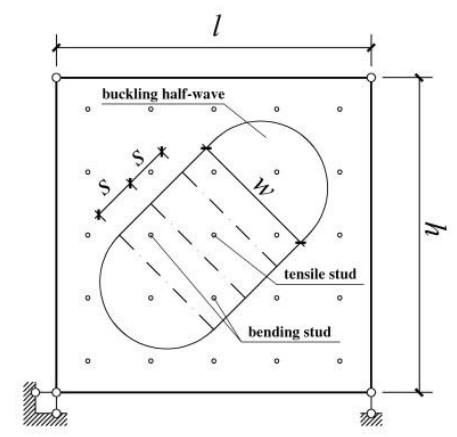

(a) Plane modification factors for tensile force demand on the headed stud, which is obtained by fitting the results from the finite element analysis.

$$
F_{\mathrm{b}}=\beta_{\mathrm{f}} \alpha s_{\mathrm{st}} t_{\mathrm{s}} f_{\mathrm{sy}} \times 10^{-3}
$$

From Fig. 14 (b), it can be concluded that a bending stud is able to be equivalent to a cantilever beam with the analysed plate strip taken as its support, which limits the bending moment of the stud to half of the plastic bending strength of the steel plate strip $\left(0.5 M_{\mathrm{sp}}\right)$ after the inelastic buckling of the infill steel plate. The plastic bending strength of the steel plate strip is calculated as $M_{\mathrm{sp}}=0.25 s t_{\mathrm{s}}^{2} f_{\mathrm{sy}}$. Accounting for the proportion between the stud bending moment $M_{\mathrm{b}}$ and $0.5 M_{\mathrm{sp}}$ as well as the effects of stud spacing $s_{\mathrm{st}}$ and the panel aspect ratio $\alpha$ on the plate strip width $s$, a relationship between the stud bending moment and internal force of the infill steel plate is established as in Eq. (2), where $M_{\mathrm{b}}$ is the stud bending moment in $\mathrm{kN} \cdot \mathrm{mm} ; f_{\mathrm{sy}}$ is the infill steel plate yield strength in MPa; $t_{\mathrm{s}}$ is the infill steel plate thickness in $\mathrm{mm} ; s_{\mathrm{st}}$ is the stud spacing in $\mathrm{mm} ; \alpha$ is the panel aspect ratio; and $\beta_{\mathrm{m}}$ is the dimensionless modification factors for tensile force demand on the headed stud, which is obtained by fitting the results from the finite element analysis.

$$
M_{\mathrm{b}}=\frac{1}{4} \beta_{\mathrm{m}} \alpha s_{\mathrm{st}} t_{\mathrm{s}}^{2} f_{\mathrm{sy}} \times 10^{-3}
$$

Fig. 14 Schematics of the interaction between stud and infill steel plate

\section{Tensile force and bending moment demands on stud}

The tensile force and bending moment demands on a stud are proposed following the criterion that the tensile or bending failure of a headed stud in a C-SPW shall not appear until the drift ratio achieves the drift limit of $2.5 \%$. To propose the formulas for the demands on stud tension and bending moment in the design of the C-SPW, the established relationship between the internal forces of the headed stud and infill steel plate in the post-buckling phase is calibrated through fitting modification factors $\beta_{\mathrm{f}}$ and $\beta_{\mathrm{m}}$ according to the predicted relevant maximum values from finite element analysis up to the drift ratio of $2.5 \%$. The predicted maximums of the tensile force and bending moment of the stud are denoted as $F_{\mathrm{eb}}$ and $M_{\mathrm{eb}}$, respectively.

\subsection{Formula for tensile force demand on stud}

At the drift ratio of $2.5 \%$, the development stage in which stud tension occurs varies. The earlier that the infill steel plate buckles, the greater the tensile force that develops in the stud. Based on the parametric study on the drift ratio of $\theta_{\mathrm{b}}$, referring to Fig. 8 , and considering the extent of influence, the development stage is can be distinguished using Eq. (3), where $\delta$ is the dimensionless variable factor; $t_{\mathrm{s}}$ is the infill steel plate thickness; $t_{\mathrm{c}}$ is the concrete panel thickness; $s_{\mathrm{st}}$ is the stud spacing; and $\alpha$ is the panel aspect ratio. When $\delta$ ranges from 1.11 to 1.53 , stud tension development is in the stage before Increase Stage 1; when $\delta$ ranges from 1.53 to 2.53 , stud tension development is in the Increase Stage 1; and when $\delta$ ranges from 2.53 to 5.07, stud tension development is in the Increase Stage 2. The stage of development of stud tension and the corresponding variable factor $\delta$ are tabulated in Table 2 .

$$
\delta=t_{\mathrm{s}}^{0.1} s_{\mathrm{st}}^{0.9} \alpha^{0.25} / t_{\mathrm{c}}
$$

Substituting $F_{\mathrm{eb}}$ for $F_{\mathrm{b}}$ in Eq. (1) yields the modification factor $\beta_{\mathrm{f}}$, as listed in Table 2. Because the slope of the stud tension-drift ratio curve is directly proportional to the stud spacing $s_{\mathrm{st}}$, steel plate thickness $t_{\mathrm{s}}$ and panel aspect ratio $\alpha$ is reflected in Eq. (1), the factor $\beta_{\mathrm{f}}$ is introduced to deal with the influence of the critical drift ratio that determines the stage of development of stud tension. Hence, $\beta_{\mathrm{f}}$ can be converted into a function of $\delta$ and is linearly fitted as Eqs. (4) and (5) for the stage before Increase Stage 2 and Increase Stage 2, respectively.

$$
\begin{array}{ll}
\beta_{\mathrm{f}}=0.004+0.002 \delta & 1.11 \leq \delta<2.53 \\
\beta_{\mathrm{f}}=0.003+0.009 \delta & 2.53 \leq \delta<5.07
\end{array}
$$

Substituting $\beta_{\mathrm{f}}$ and Eq. (3) into Eq. (1), the formula for tensile force demand on stud $F_{\mathrm{b}}$ in $\mathrm{kN}$ is yielded as Eqs. (6) and (7), where $\alpha, f_{\mathrm{sy}}, t_{\mathrm{s}}, s_{\mathrm{st}}$ and $t_{\mathrm{c}}$ are stated in the preceding sections.

$$
F_{\mathrm{b}}=s_{\mathrm{st}} t_{\mathrm{s}} f_{\mathrm{sy}}\left(0.004 \alpha+0.002 \alpha^{1.25} \frac{t_{\mathrm{s}}^{0.1} s_{\mathrm{st}}^{0.9}}{t_{\mathrm{c}}}\right) \times 10^{-3}
$$

$1.11 \leq \delta<2.53$

$F_{\mathrm{b}}=s_{\mathrm{st}} t_{\mathrm{s}} f_{\mathrm{sy}}\left(0.009 \alpha+0.003 \alpha^{1.25} \frac{t_{\mathrm{s}}^{0.1} s_{\mathrm{st}}^{0.9}}{t_{\mathrm{c}}}\right) \times 10^{-3}$

$2.53 \leq \delta<5.07$

The results of Eq. (3) with regard to the calibration and finite element analysis results are illustrated in Fig. 15, where the $F_{\mathrm{eb}}$ is represented as a point, 
and the calculations using Eqs. (6) and (7) produce a solid line. It can be observed that the minimum, maximum and average of the differences between the finite element analysis results and the results of Eq. (3) are $0.01 \%, 25 \%$ and $3 \%$, respectively, where the predicted data $\left(F_{\mathrm{eb}}\right)$ with relatively large differences are almost below the solid line. This demonstrates that Eqs. (6) and (7) for the tensile force demand on a stud can be used to estimate the maximum stud tension of the C-SPW up to a $2.5 \%$ drift ratio with reasonable accuracy and conservatism.

Table 2

Calibration of stud tensile force from FEM

\begin{tabular}{|c|c|c|c|c|c|}
\hline Specimens & Development stage & $\delta$ & $F_{\mathrm{eb}}(\mathrm{kN})$ & $\beta_{\mathrm{f}} \times 10^{-3}$ & $F_{\mathrm{b}}(\mathrm{kN})$ \\
\hline N4-B & Increase Stage 2 & 3.62 & 50.7 & 19.2 & 52.5 \\
\hline N4-D22 & Increase Stage 2 & 3.62 & 50.5 & 19.1 & 52.5 \\
\hline N4-TS10 & Increase Stage 2 & 3.48 & 36.8 & 20.9 & 34.3 \\
\hline N4-TS20 & Increase Stage 2 & 3.73 & 60.5 & 17.2 & 71.1 \\
\hline N4-TC50 & Increase Stage 2 & 5.06 & 58.2 & 22.0 & 64.0 \\
\hline N4-TC100 & Increase Stage 2 & 2.54 & 47.3 & 17.9 & 43.9 \\
\hline N5-B & Increase Stage 2 & 2.96 & 38.5 & 18.2 & 37.8 \\
\hline N5-D22 & Increase Stage 2 & 2.96 & 37.4 & 17.7 & 37.8 \\
\hline N5-TS10 & Increase Stage 2 & 2.84 & 21.3 & 15.1 & 24.7 \\
\hline N5-TS20 & Increase Stage 2 & 3.05 & 49.5 & 17.6 & 51.2 \\
\hline N5-TC50 & Increase Stage 2 & 4.15 & 45.5 & 21.5 & 45.3 \\
\hline N5-TC100 & Increase Stage 1 & 2.07 & 15.7 & 7.4 & 17.2 \\
\hline N6-B & Increase Stage 1 & 2.51 & 14.4 & 8.2 & 15.9 \\
\hline N6-D22 & Increase Stage 1 & 2.51 & 13.8 & 7.8 & 15.9 \\
\hline N6-TS10 & Increase Stage 1 & 2.42 & 13.4 & 11.4 & 10.4 \\
\hline N6-TS20 & Increase Stage 2 & 2.59 & 32.1 & 13.7 & 39.4 \\
\hline N6-TC50 & Increase Stage 2 & 3.52 & 25.7 & 14.6 & 34.5 \\
\hline N6-TC100 & Increase Stage 1 & 1.76 & 10.3 & 5.8 & 13.3 \\
\hline N10-B & Increase Stage 1 & 1.59 & 6.8 & 6.4 & 7.6 \\
\hline N10-D22 & Increase Stage 1 & 1.59 & 6.6 & 6.3 & 7.6 \\
\hline N10-TS10 & Pre-buckling & 1.52 & 5.9 & 8.5 & 5.0 \\
\hline N10-TS20 & Increase Stage 1 & 1.63 & 11.5 & 8.2 & 10.3 \\
\hline N10-TC50 & Increase Stage 1 & 2.22 & 10.2 & 9.6 & 8.9 \\
\hline N10-TC100 & Pre-buckling & 1.12 & 5.3 & 6.2 & 6.6 \\
\hline L6-B & Increase Stage 1 & 2.49 & 9.3 & 8.8 & 9.5 \\
\hline L6-TS10 & Increase Stage 1 & 2.39 & 5.6 & 7.9 & 6.2 \\
\hline L6-TS20 & Increase Stage 2 & 2.57 & 25.1 & 17.7 & 23.5 \\
\hline
\end{tabular}

\subsection{Formula for stud bending moment demand}

At the drift ratio of $2.5 \%$, the stud bending moment development stage can also be distinguished using Eq. (3). When $\delta$ ranges from 1.11 to 1.53 , the stud bending moment development is in the stage before Increase Stage; when $\delta$ ranges from 1.53 to 2.53 , the stud bending moment development is in the Increase Stage; and when $\delta$ ranges from 2.53 to 5.07, the stud bending moment development is in the Plateau Stage.

Substituting the maximum stud bending moment $M_{\mathrm{eb}}$ obtained from finite element analysis for $M_{\mathrm{b}}$ in Eq. (2), the modification factor $\beta_{\mathrm{m}}$ is obtained as listed in Table 3. For the Increase Stage of stud bending, the effects of stud spacing $s_{\mathrm{st}}$, infill steel plate thickness $t_{\mathrm{s}}$ and panel aspect ratio $\alpha$ are contained in Eq. (2). Therefore, the modification factor for stud bending moment $\beta_{\mathrm{m}}$ is employed to capture the effects of stud diameter $d_{\text {st }}$ and overall thickness of the concrete panels $t_{\mathrm{c}}$ on the maximum stud bending moment $M_{\mathrm{eb}}$. According to the parameter analysis on stud bending moment and fitting $\beta_{\mathrm{m}}$ by the variable $d_{\mathrm{st}}{ }^{2} /$ $t_{\mathrm{c}}{ }^{2}$, formulas for $\beta_{\mathrm{m}}$ in the stage before Increase Stage and Increase Stage are shown in Eqs. (8) and (9), respectively. Substituting Eqs. (8) and (9) into Eq. (2), the bending moment demands on the headed stud $M_{\mathrm{b}}$ in $\mathrm{kN} \cdot \mathrm{mm}$ in the stage before the Plateau Stage are yielded in Eqs. (10) and (11), where $\alpha, f_{\mathrm{sy}}, t_{\mathrm{s}}, s_{\mathrm{st}}, t_{\mathrm{c}}$ and $d_{\text {st }}$ are stated previously.

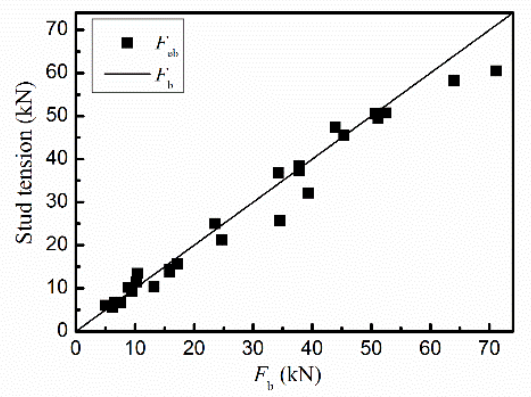

Fig. 15 Calibration of the tensile force demand on stud

$$
\begin{gathered}
\beta_{\mathrm{m}}=2.8 \frac{d_{\mathrm{st}}^{2}}{t_{\mathrm{c}}^{2}} \\
\beta_{\mathrm{m}}=1.9 \frac{d_{\mathrm{st}}^{2}}{t_{\mathrm{c}}^{2}} \\
M_{\mathrm{b}}=0.7 \alpha s_{\mathrm{st}} t_{\mathrm{s}}^{2} f_{\mathrm{y}} \frac{d_{\mathrm{st}}^{2}}{t_{\mathrm{c}}^{2}} \times 10^{-3} \\
M_{\mathrm{b}}=0.475 \alpha s_{\mathrm{st}} t_{\mathrm{s}}^{2} f_{\mathrm{y}} \frac{d_{\mathrm{st}}^{2}}{t_{\mathrm{c}}^{2}} \times 10^{-3} \\
1.53 \leq \delta<2.53<2.53
\end{gathered}
$$

From the results of the parameter analysis, it is known that the bending moment of a stud in the Plateau Stage is mainly determined by stud diameter $d_{\mathrm{st}}$ as well as infill steel plate thickness $t_{\mathrm{s}}$. The roles that $\beta_{\mathrm{m}}$ plays include introducing the influences of $d_{\mathrm{st}}$, abating the extent of influence of $t_{\mathrm{s}}$ and eliminating the influences of $s_{\mathrm{st}}$ as well as $\alpha$. Fitting $\beta_{\mathrm{m}}$ by the variable of $d_{\mathrm{st}}^{2.8} /\left(\alpha s_{\mathrm{st}}{ }_{\mathrm{s}}{ }^{1.8}\right)$ yields Eq. (12). In the Plateau Stage, the bending moment demand on a stud in $\mathrm{kN} \cdot \mathrm{mm}$ is proposed by substituting Eq. (12) into Eq. (2), as shown in Eq. (13).

$$
\begin{array}{ll}
\beta_{\mathrm{m}}=1.08 \frac{d_{\mathrm{st}}^{2.8}}{\alpha s_{\mathrm{st}} t_{\mathrm{s}}^{1.8}} & 2.53 \leq \delta<5.07 \\
M_{\mathrm{b}}=0.27 d_{\mathrm{st}}^{2.8} t_{\mathrm{s}}^{0.2} f_{\mathrm{sy}} \times 10^{-3} & 2.53 \leq \delta<5.07
\end{array}
$$

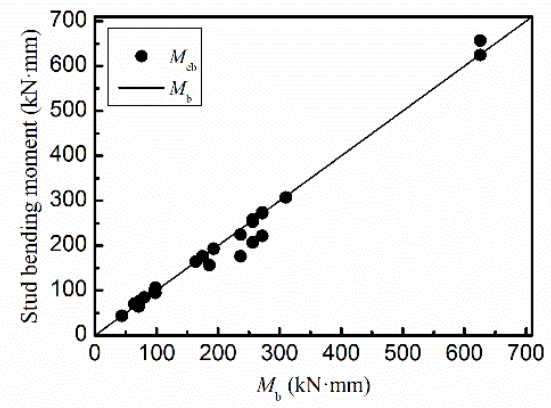

Fig. 16 Calibration of the bending moment demand on stud

The results obtained from calibrating Eq. (3) and the finite element 
analysis results are displayed in Fig. 16, where the $M_{\mathrm{eb}}$ is represented as a point and the calculations of Eqs. (10) and (11) and (13) produce a solid line. It can be observed that the minimum, maximum and average of the differences between the finite element analysis and Eq. (3) are 0.01\%, 29\% and $2.6 \%$, respectively, where the predicted data $\left(M_{\mathrm{eb}}\right)$ with relatively large differences are below the solid line. This indicates that Eqs. (10), (11) and (13) for the bending moment demand on a stud can estimate the maximum stud bending moment of a C-SPW up to a $2.5 \%$ drift ratio with reasonable accuracy and conservatism.

Table 3

Calibration of stud bending moment from FEM

\begin{tabular}{|c|c|c|c|c|c|}
\hline Specimens & Development stage & $\delta$ & $\begin{array}{c}M_{\mathrm{eb}} \\
(\mathrm{kN} \cdot \mathrm{mm})\end{array}$ & $\beta_{\mathrm{m}} \times 10^{-3}$ & $\begin{array}{c}M_{\mathrm{b}} \\
(\mathrm{kN} \cdot \mathrm{mm})\end{array}$ \\
\hline N4-B & Plateau Stage & 3.62 & 257.0 & 25.9 & 256.6 \\
\hline N4-D22 & Plateau Stage & 3.62 & 657.0 & 66.2 & 625.8 \\
\hline N4-TS10 & Plateau Stage & 3.48 & 224.2 & 50.9 & 236.6 \\
\hline N4-TS20 & Plateau Stage & 3.73 & 273.2 & 15.5 & 271.8 \\
\hline N4-TC50 & Plateau Stage & 5.06 & 258.0 & 26.0 & 256.6 \\
\hline N4-TC100 & Plateau Stage & 2.54 & 254.2 & 25.6 & 256.6 \\
\hline N5-B & Plateau Stage & 2.96 & 253.0 & 31.9 & 256.6 \\
\hline N5-D22 & Plateau Stage & 2.96 & 624.7 & 78.8 & 625.8 \\
\hline N5-TS10 & Plateau Stage & 2.84 & 176.0 & 49.9 & 236.6 \\
\hline N5-TS20 & Plateau Stage & 3.05 & 272.2 & 19.3 & 271.8 \\
\hline N5-TC50 & Plateau Stage & 4.15 & 257.0 & 32.4 & 256.6 \\
\hline N5-TC100 & Increase Stage & 2.07 & 100.0 & 12.6 & 97.5 \\
\hline N6-B & Increase Stage & 2.51 & 164.0 & 24.8 & 164.4 \\
\hline N6-D22 & Increase Stage & 2.51 & 307.0 & 46.4 & 310.1 \\
\hline N6-TS10 & Increase Stage & 2.42 & 76.5 & 26.0 & 72.9 \\
\hline N6-TS20 & Plateau Stage & 2.59 & 221.3 & 18.8 & 271.8 \\
\hline N6-TC50 & Plateau Stage & 3.52 & 207.2 & 31.3 & 256.6 \\
\hline N6-TC100 & Increase Stage & 1.76 & 84.3 & 12.8 & 80.4 \\
\hline N10-B & Increase Stage & 1.59 & 94.5 & 23.8 & 98.4 \\
\hline N10-D22 & Increase Stage & 1.59 & 156.2 & 39.3 & 186.1 \\
\hline N10-TS10 & Pre-buckling & 1.52 & 70.2 & 39.7 & 64.5 \\
\hline N10-TS20 & Increase Stage & 1.63 & 175.8 & 24.9 & 175.0 \\
\hline N10-TC50 & Increase Stage & 2.22 & 192.7 & 48.6 & 192.9 \\
\hline N10-TC100 & Pre-buckling & 1.12 & 63.7 & 16.1 & 71.1 \\
\hline L6-B & Increase Stage & 2.49 & 105.9 & 26.7 & 98.4 \\
\hline L6-TS10 & Increase Stage & 2.39 & 43.1 & 24.5 & 43.7 \\
\hline L6-TS20 & Plateau Stage & 2.57 & 271.8 & 38.6 & 271.8 \\
\hline
\end{tabular}

\section{Conclusions}

The objective of this paper was to propose formulas for the tension and bending moment demands on headed studs in the design of C-SPWs. The tensile forces and bending moments of studs in a C-SPW subjected to a lateral load are researched using the finite element method. The development and distributions of stud tension and bending moment as well as the interaction between studs and infill steel plates are analysed with five varying design parameters including concrete panel thickness, infill steel plate thickness, panel aspect ratio (the ratio of height to width) and number of studs. Based on the analysis results, available fitting formulas for the demands on stud tension and bending moment in the design of C-SPWs are proposed.
The conclusions produced in this paper are presented as follows:

Stud tension and bending moment become marked in the post-buckling phase of the infill steel plate resulting from significant, relative out-of-plane deformation between the steel plate and concrete panel.

The critical tensile studs are concentrated in the middle of buckling half-wave, whereas the critical bending studs are located at the boundary of the buckling half-wave. The coupling effect between the tensile force and bending moment is minimal.

Stud tension development is divided into two stages, which incorporate the transitory and rapidly increasing phases of tension as well as the linearly increasing. Stud bending moment development is divided into two stages: linearly increasing and approximately constant.

At the required drift ratio of $2.5 \%$ per ASCE, the maximum values of stud tension and bending moment are determined by the critical drift ratio corresponding to the onset of infill steel plate buckling, the development stages in which these values are located as well as their rate of development.

The rate of development of stud tension and bending moment transferred through the concrete panel are determined by the transverse component of axial forces along the buckling half-wave of the infill steel plate and the plastic moment at both ends of the buckling half-wave.

The formulas for the tensile force and bending moment demands on headed studs when the drift ratio of a C-SPW is limited to $2.5 \%$ are proposed with reasonable accuracy and conservatism. These formulas can be used in the seismic design of C-SPWs.

\section{Acknowledgement}

This research is funded by the National Natural Science Foundation of China (grant number 51678382), which is gratefully acknowledged.

\section{References}

[1] Astaneh-Asl A., "Seismic behavior and design of composite steel plate shear walls". Steel Tips Report, Structural Steel Educational Council, USA, 2002.

[2] Zhao Q.H, and Astaneh-Asl A., "Cyclic behavior of traditional and innovative composite shear walls", Journal of Structural Engineering, 130(2), 271-284, 2004.

[3] Arabzadeh A., Soltani M. and Ayazi A., "Experimental investigation of composite shear walls under shear loadings", Thin-Walled Structures, 49, 842-854, 2011.

[4] Rassouli B., Shafaei S., Ayazi A., et al., "Experimental and numerical study on steel-concrete composite shear wall using light-weight concrete", Journal of Constructional Steel Research, 126, 117-128, 2016.

[5] Seismic provisions for structural steel buildings (ANSI/AISC 341), American Institute of Steel Construction, Chicago, IL, USA, 2010.

[6] Rahai A. and Hatami F., "Evaluation of composite shear wall behavior under cyclic loadings", Journal of Constructional Steel Research, 65, 1528-1537, 2009.

[7] Shafaei S., Ayazi A. and Farahbod F., "The effect of concrete panel thickness upon composite steel plate shear walls", Journal of Constructional Steel Research, 117, 81-90, 2016.

[8] Rahnavard R., Hassanipour A. and Mounesi A., "Numerical study on important parameters of composite steel-concrete shear walls", Journal of Constructional Steel Research, 121, 441-456, 2016.

[9] Dey S. and Bhowmick A.K., "Seismic performance of composite plate shear walls", Structures, 6, 59-72, 2016

[10] Simith S.T., Bradford M.A. and Oehlers D.J., "Elastic buckling of unilaterally constrained rectangular plates in pure shear", Engineering Structures, 21, 443-453, 1999.

[11] Arabzade A., Moharami H. and Ayazi A., "Local elastic buckling coefficients of steel plates in composite steel plate shear walls", Scientia Iranica, 18(1), 9-15, 2011 (A)

[12] Guo L.H., Li R., Rong Q., et al., "Cyclic behavior of SPSW and CSPSW in composite frame", Thin-Walled Structures, 51, 39-52, 2012.

[13] Dong Q.L. and Guo Y.L, "Ultimate shear capacity of buckling-restrained steel plate shear walls, Pacific Structural Steel Conference, Steel Structures in Natural Hazarrds, Wairakei, New Zealand, 335-340, 2007.

[14] Guo Y.L., Dong Q.L., "Static behavior of buckling-restrained steel plate shear walls", The 6th International Conference on Tall Buildings, The University of Hong Kong, Hong Kong, China, 666-670, 2005.

[15] Jin S.S., Ou J.P. and Richard J.Y., "Stability of buckling-restrained steel plate shear walls with inclined-slots: Theoretical analysis and design recommendations", Journal of Constructional Steel Research, 117:13-23, 2016.

[16] Wei M.W., Richard Liew J.Y. and Fu X.Y., "Panel action of novel partially connected buckling-restrained steel plate shear walls", Journal of Constructional Steel Research, 128 , 483-497, 2017.

[17] Pallarés L. and Hajjar J.F., "Headed steel stud anchors in composite structures, Part II: Tension and interaction", Journal of Constructional Steel Research, 66, 213-228, 2010

[18] Lin Z.F., Liu Y.Q. and Roeder C.W., "Behavior of stud connections between concrete slab and steel girders under transverse bending moment", Engineering Structures, 117, 130-144, 2016.

[19] Building code requirements for structural concrete (ACI 318), American Concrete Institute, Farmington Hills, Michigan, USA, 2011.

[20] Code requirements for nuclear safety related concrete structures (ACI 349), American Concrete Institute, Farmington Hills, Michigan, USA, 2006.

[21] PCI design handbook: Precast and prestressed concrete, Precast/Prestressed Concrete Institute, Chicago ( IL), USA, 2004 
[22] Qi Y., Gu Q., et al., "Shear force demand on headed stud for the design of composite steel plate shear wall", Engineering Structures, 148, 780-792, 2017. http://dx.doi.org/10.1016/j.engstruct.2017.07.023.

[23] Qi Y., Gu Q., et al., "Concrete panel thickness demand for the design of composite steel plate shear wall", The Structural Design of Tall and Special Buildings, 28(8), 2019. http://doi.org/ /10.1002/tal. 1605 .

[24] Hibbitt K., Sorensen., “ABAQUS/Standard User's Manual (Version 6.12)”, RI: HKS Inc., Pawtucket, USA, 2012.

[25] Lubiner J., Oliver J., Oller S., et al., "A plastic-damage model for concrete", International Journal of Solids and Structures, 25(3), 399-326, 1989.

[26] Lee B.J., Fenves G.L., Member, ASCE, "Plastic-damage model for cyclic loading of concrete structures", Journal of Engineering Mechanics, 124(8), 892-990 , 1998.

[27] Zhang K., Varma A.H., Malushte S.R., et al., "Effect of shear connectors on local buckling and composite action in steel concrete composite walls", Nuclear Engineering and Design, 269, 231-239, 2014

[28] Cho S.G., Park W.K., So G.H., et al., "Seismic capacity estimation of steel plate concrete (SC) shear wall specimens by nonlinear static analyses", KSCE Journal of Civil Engineering, 19(3), 698-709, 2015

[29] Epackachi S., Whittaker A.S., Varma A.H., et al., "Finite element modeling of steel-plate concrete composite wall piers". Engineering Structures. 100, 369-384. 2015.

[30] Epackachi S., Whittaker A.S. and Aref A., "Seismic analysis and design of steel-plate concrete composite shear wall piers", Engineering Structures, 133, 105-123, 2017.

[31] Nguyen N.H. and Whittaker A.S., "Numerical modeling of steel-plate concrete composite shear walls", Engineering Structures, 150, 1-11, 2017.

[32] Minimum Design Loads for Buildings and Other Structures (SEI/ASCE 7), American Society of Civil Engineers, Virginia, USA, 2010. 